Int. J. Electrochem. Sci., 13 (2018) 2627 - 2640

International Journal of

ELECTROCHEMICAL

SCIENCE

www.electrochemsci.org

\title{
Corrosion Inhibition of Mild Steel by S-benzyl-O,O'- dialkyldithiophosphates in HCl Solution
}

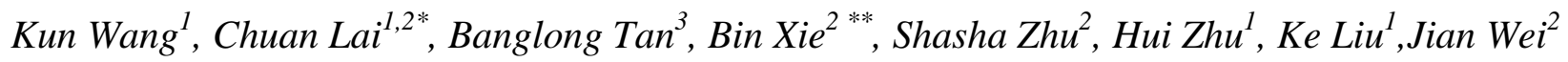 \\ ${ }^{1}$ School of Chemistry and Chemical Engineering, Eastern Sichuan Sub-center of National Engineering \\ Research Center for Municipal Wastewater Treatment and Reuse, Sichuan University of Arts and \\ Science, Dazhou 635000, PR China \\ ${ }^{2}$ College of Chemistry and Environmental Engineering, Institute of Functional Materials, Material \\ Corrosion and Protection Key Laboratory of Sichuan Province, Sichuan University of Science and \\ Engineering, Zigong 643000, PR China \\ ${ }^{3}$ DaZhou Quality Technical Supervision and Inspection Testing Center, Dazhou 635000, PR China \\ *E-mail: laichuanemail@163.com \\ **E-mail: xiebinsuse@163.com
}

doi: $10.20964 / 2018.03 .06$

Received: 16 October 2017 / Accepted: 9 December 2017 / Published: 5 February 2018

In present work, the target compounds of S-benzyl-O,O'-dialkyldithiophosphates including S-benzylO,O'-diphenyldithiophosphate (Inhi-1), S-benzyl-O,O'-dibenzyldithiophosphate (Inhi-2), S-benzylO,O'-di(2-phenylethyl)dithiophosphate(Inhi-3) and S-benzyl-O,O'-di(4-methylphenyl)dithiophosphate (Inhi-4) were prepared, which acting as corrosion inhibitor for mild steel (MS) in $\mathrm{HCl}$ solution were investigated by weight loss measurement, potentiodynamic polarization measurement and electrochemical impedance spectroscopy. The potentiodynamic polarization measurement indicates that the four synthesized compounds are all the mixed-type inhibitor for MS corrosion in $\mathrm{HCl}$ solution. Furthermore, all measurements in this study show that the inhibition efficiency increases with inhibitor concentration increasing. Weight loss measurement reveals that inhibition efficiency decreases with $\mathrm{HCl}$ concentration and temperature increasing. In addition, the adsorption of Inhi-1, Inhi-2, Inhi-3 and Inhi-4 on MS surface obeys Langmuir isotherm, which are mixed adsorption involving both physisorption and chemisorption.

Keywords: Acid; Corrosion; Inhibition; Synthesis; Mild steel; Polarization; Adsorption.

\section{$\underline{\text { FULL TEXT }}$}

(C) 2018 The Authors. Published by ESG (www.electrochemsci.org). This article is an open access article distributed under the terms and conditions of the Creative Commons Attribution license (http://creativecommons.org/licenses/by/4.0/). 